\title{
Penggunaan Dual-Layer Substrate untuk Meningkatkan Bandwidth Antena Mikrostrip pada Frekuensi LTE
}

\author{
Rudy Fernandez* , Febrian Akbar Pratama \\ Jurusan Teknik Elektro, Fakultas Teknik, Universitas Andalas \\ *Corresponding author, e-mail: rfernandez@ft.unand.ac.id
}

\begin{abstract}
Abstrak - Bandwidth yang sempit merupakan salah satu masalah utama dari suatu antena mikrostrip. Penelitian ini bertujuan untuk mendesain antenna mikrostrip dengan bandwith yang lebih lebar. Penambahan bandwidth dilakukan dengan menerapkan dual-layer substrat. Lapisan bawah dibentuk dari rancangan antena mikrostrip circular dengan menggunakan formula yang berlaku untuk mendapatkan dimensi awalnya. Jika parameter antenna hasil simulasinya sudah memenuhi persyaratan yang ditentukan, maka dimensi patchnya digunakan sebagai landasan untuk membentuk lapisan atas rancangan antena namun tanpa ground plane. Antena ini dirancang dengan menggunakan substrat FR4 yang memiliki ketebalan 1,6 mm dengan konstanta dielektrik 4,3. Hasil simulasi dari rancangan antenna dual-layer pada frekuensi band 40 LTE menunjukkan adanya penambahan bandwidth sebesar $46 \%$ dengan nilai return loss $-23,45 \mathrm{~dB}$, gain antenna $0.34 \mathrm{~dB}$ dan pola radiasi directional.
\end{abstract}

Kata Kunci : Microstrip Antenna, Return Loss dan Dual-layer

\begin{abstract}
Narrow bandwidth is one of the problems in a microstrip antenna. Bandwidth enhancement is proposed by applying dual-layer in the substrate. The bottom layer is made from a single-layer circular microstrip antenna design by applying the formula to get an initial dimension and then it is simulated by an EM Simulator to verify its performance whether meet the specific requirement. The dimension of optimized design is used as a dimension for the top layer but without the ground plane. The antenna uses substrate FR4 which has thickness of $1.6 \mathrm{~mm}$ with dielectric constant of 4.3 . The simulation result of the dual-layer antenna in frequency band 40 LTE shows that there is an additional bandwidth of $46 \%$ with return loss $23.45 \mathrm{~dB}$, antenna gain $0.34 \mathrm{~dB}$ and directional radiation pattern.
\end{abstract}

Keywords : Microstrip Antenna, Return Loss and Dual-layer

\section{Pendahuluan}

Teknologi 4G LTE (Long Term Evolution) merupakan pengembangan dari teknologi telepon seluler 3G (third-generation) dan 2G (secondgeneration). Layanan ini pertama kali diluncurkan di Indonesia pada tahun 2013. Teknologi 4G di Indonesia pada saat ini bekerja pada frekuensi $1800 \mathrm{MHz}$ dan $2300 \mathrm{MHz}$ [1]. Pita frekuensi $2300 \mathrm{MHz}$ disebut juga Band 40 ini memiliki rentang frekuensi $2300 \mathrm{MHz}$ hingga $2400 \mathrm{MHz}$.

Sistem komunikasi seluler yang bekerja pada band 40, menggunakan antena untuk mengirimkan dan menerima informasi dalam bentuk gelombang radio. Antena yang digunakan memiliki ukuran yang kecil, tipis, dan ringan. Antena mikrostrip merupakan sebuah antena yang memenuhi kriteria tersebut [2]. Pembuatan antena ini menggunakan teknologi printedcircuit, sehingga dapat dibuat dalam berbagai macam bentuk. Disamping kelebihannya, antena ini hanya mampu menangani daya yang rendah dan bandwidthnya sempit (narrow band) [2].

Berbagai metode memiliki telah diusulkan untuk meningkatkan bandwidth. Pemilihan metode pencatuan merupakan hal penting dalam desain antena untuk mendapatkan parameter yang diharapkan, seperti pencatuan coupled menghasilkan bandwidth impedansi sekitar 13\%, tapi tidak begitu mudah dibuat karena membutuhkan keselarasan yang tepat pada saat difabrikasi [3]. Metode lain yang digunakan untuk meningkatkan bandwidth biasanya dari variasi dari berbagai pendekatan. Antara lain adalah pendekatan secara geometri pada antena dengan pemberian shorts dan slots untuk 
menciptakan resonansi atau dikenal dengan sebutan defected ground structure (DGS) [4-5]. Kemudian penggunaan struktur Electromagnetic Band Gap (EBG) [6-7]. Terakhir, penggunaan metamaterial dengan negative refractive index juga merupakan pilihan tapi membutuhkan tantangan tersendiri dalam menganalisanya [8].

Balanis [2] menyarankan bahwa, dengan meningkatkan ketebalan substrat, peningkatan bandwidth bisa dimungkinkan. Salah satu cara meningkatkan ketebalan adalah pemberian substrat tambahan sehingga menjadi 4 layers dengan posisi patch antenna pada lapisan 2 dan lapisan 4 [9]. Pada penelitian ini digunakan 2 lapisan saja. Lapisan bawah merupakan sebuah antenna mikrostrip circular yang bertindak sebagai pemicu dan lapisan atas terdiri patch yang sama tanpa ground plane.

\section{Perancangan Antena}

Bentuk antena mikrostrip yang dipilih adalah circular karena efektif untuk dirancang dalam konfigurasi multi-layer [10], sesuai dengan bentuk yang ditunjukkan pada Gambar 1. Pada gambar ini memperlihatkan bentuk dari antena mikrostrip dengan patch lingkaran, dimana $a$ merupakan radius patch, $\mathrm{t}$ merupakan ketebalan patch, h merupakan ketebalan substrate, dan $\varepsilon_{\mathrm{r}}$ adalah konstanta dielektrik substrate.

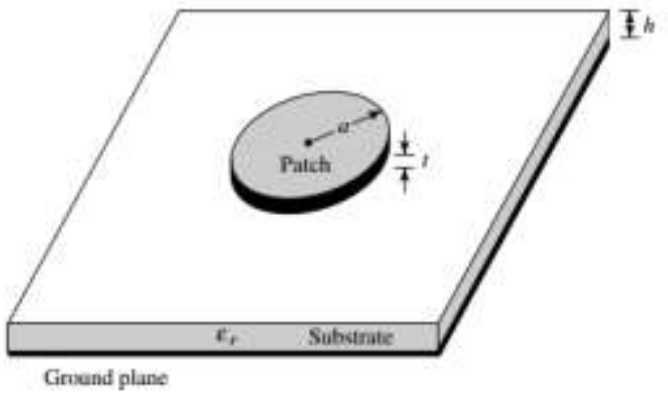

Gambar 1. Bentuk geometris antena mikrostrip circular

Dimensi radius dari patch lingkaran pada antena mikrostrip di atas dapat dihitung dengan persamaan 1 berikut.

$$
a=\frac{F}{\left\{1+\frac{2 h}{\pi \varepsilon_{r} F}\left[\ln \left(\frac{\pi F}{2 h}\right)+1,7726\right]\right\}^{\frac{1}{2}}}
$$

Dengan $F$ adalah fungsi logaritmik dari elemen peradiasi dan ditunjukkan oleh persamaan 2 berikut:

$$
F=\frac{8,791 \times 10^{9}}{f_{r} \sqrt{\varepsilon_{r}}}
$$

Substrate yang digunakan untuk dalam penelitian ini adalah FR4 Epoxy dengan ketebalan 1,6 mm, konstanta dielektrik 4.4 dan dielectric loss tangent 0.02 . Hasil perhitungan menunjukkan bahwa untuk antenna yang bekerja pada frekuensi resonansi $2.35 \mathrm{GHz}$ maka radiusnya sekitar $17 \mathrm{~mm}$ dengan $\mathrm{F}=1.7833$. Lokasi feed point ditetapkan dari titik tengah patch sejauh $0.5 \mathrm{~mm}$ dari radius patch yaitu 8.5 $\mathrm{mm}$. Dengan memperhatikan ground plane dari rancangan, maka dimensi totalnya adalah $44 \mathrm{~mm}$ x $44 \mathrm{~mm}$ seperti pada gambar 2 .

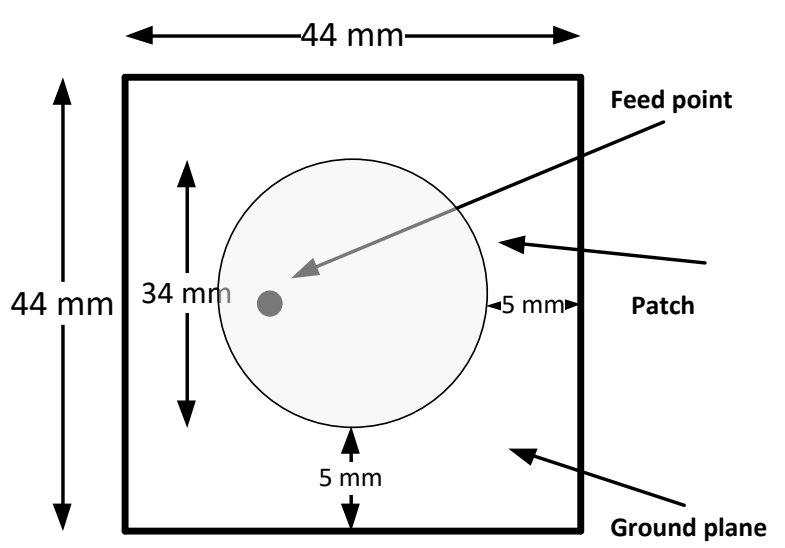

Gambar 2. Rancangan antena mikrostrip circular hasil perhitungan

Kinerja dari sebuah antena mikrostrip dilihat dari parameter return loss dan VSWR nya. Jika return lossnya bernilai $<-10 \mathrm{~dB}$ dan $\mathrm{VSWR} \leq 2$ pada frekuensi kerja yang diharapkan dan pola radiasi yang ditetapkan yaitu directional untuk aplikasi teknologi LTE, maka dikatakan antenna ini telah bekerja dengan baik. Jika kinerja dari rancangan hasil perhitungan ini belum memenuhi persyaratan, maka rancangan tersebut perlu dioptimasi.

Rancangan antena hasil optimasi ini dijadikan sebagai lapisan bawah. Sedangkan lapisan atas akan menggunakan dimensi patch yang sama seperti yang ada pada lapisan bawah. Bentuk rancangan antena dual-layer pada penelitian ini seperti pada gambar 3 berikut. 


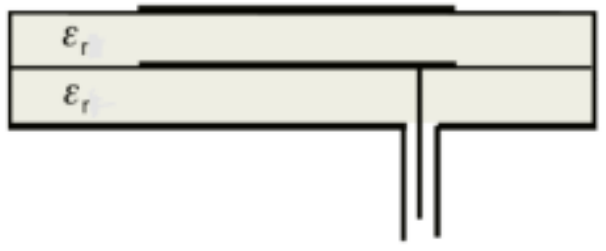

Gambar 3. Bentuk geometris rancangan antena mikrostrip dual-layer

\section{Hasil dan Pembahasan}

Rancangan hasil perhitungan disimulasikan dengan menggunakan suatu EM simulator untuk diuji kinerjanya lebih dahulu. Dari hasil simulasi menunjukkan bahwa tersebut memperlihatkan return loss seperti pada gambar 4.:

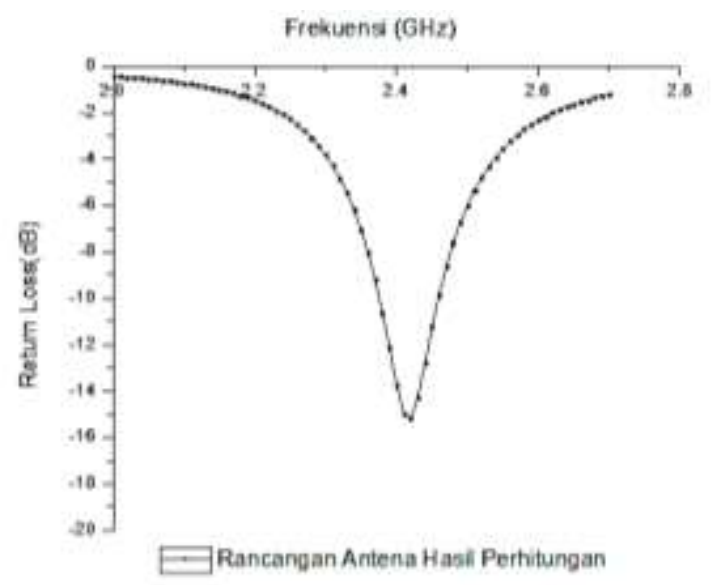

Gambar 4. Return loss antena hasil perhitungan

Pada gambar diatas cakupan frekuensi yang memenuhi parameter tersebut adalah dari 2.375 $\mathrm{GHz}$ hingga $2.458 \mathrm{MHz}$. Hal ini belum memenuhi cakupan $2.300-2.400 \mathrm{MHz}$ yang diharapkan.

Rancangan antena hasil perhitungan dioptimasi dengan menguji posisi feeding point, dimensi ground plane dan jari-jari patch yang digunakan. Agar diperoleh hasil yang optimum, posisi awal feeding point bertambah sejauh 0.2 mm dari titik tengah patch, jari-jari patch menjadi $7.5 \mathrm{~mm}$ dan dimensi ground plane menjadi 50 $\mathrm{mm} \times 50 \mathrm{~mm}$.

Dengan menggunakan perubahan posisi dan dimensi dari hasil optimasi, hasil simulasi antena menunjukkan return loss, bandwidth dan gain seperti yang ditunjukkan pada tabel 1 berikut.
Tabel 1. Kinerja antena hasil optimasi

\begin{tabular}{|c|c|c|c|}
\hline No & Parameter & Target & Hasil \\
\hline 1 & Return loss $(\mathrm{dB})$ & $\leq-10$ & $-24,28$ \\
\hline 2 & $\begin{array}{l}\text { Bandwidth } \\
(\mathrm{MHz})\end{array}$ & 100 & 73,2 \\
\hline 3 & $\begin{array}{c}\text { Pita frekuensi } \\
\text { kerja }(\mathrm{MHz})\end{array}$ & $2300-2400$ & $2319,7-2392,9$ \\
\hline 4 & Gain $(\mathrm{dB})$ & $\geq 0$ & $0.11-0.55$ \\
\hline
\end{tabular}

Pada tabel 1 dapat dilihat nilai return loss dan gain sudah memenuhi parameter yang disyaratkan. Namun bandwidth dari antena optimasi ini masih belum mencakup jaringan $4 \mathrm{G}$ LTE, sehingga perlu dilakukan teknik dual-layer pada subtract yang bertujuan untuk meningkatkan bandwidth dari antena tersebut.

Selanjutnya rancangan antena dual-layer seperti pada gambar 3 sebelumnya disimulasi kan untuk dilihat kinerjanya. Nilai return loss dan VSWR yang dicapai oleh rancangan antena duallayer dapat dilihat pada gambar 6 dan 7 berikut.

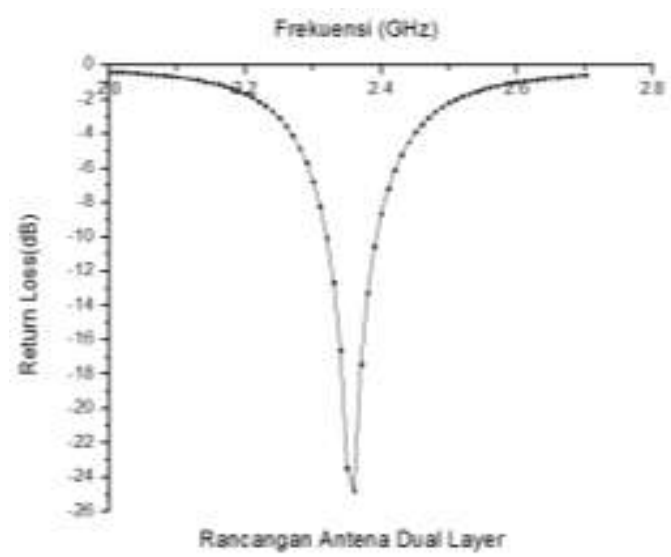

Gambar 6. Return loss antena dual-layer

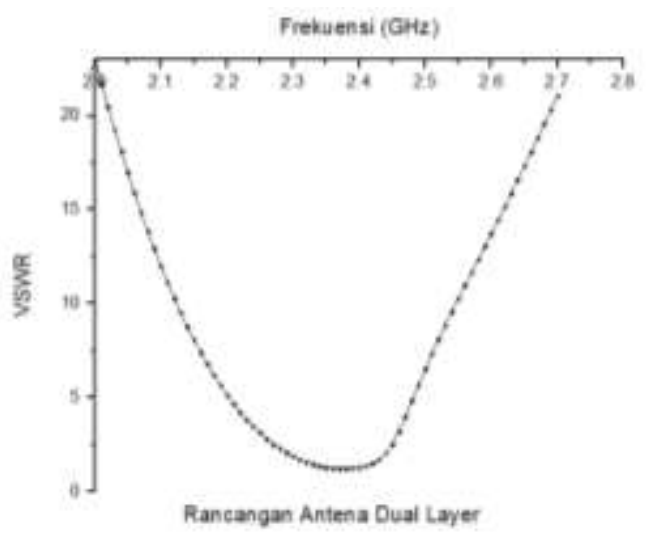

Gambar 7. VSWR antena dual-layer

https://doi.org/10.25077/jnte.v7n2.505.2018 jnte.ft.unand.ac.id 
Pada gambar 6 ditunjukkan bahwa nilai return loss terkecil pada rancangan antenna dual-layer yaitu $-24.78 \mathrm{~dB}$ terjadi pada frekuensi $2.36 \mathrm{GHz}$. Sedangkan pada frekuensi tengahnya bernilai 23.45 dB. Kemudian pada gambar 7 dapat dilihat nilai VSWR yang diperoleh berada di rentang 1.3 - 1.9 pada rentang frekuensi target.

Nilai gain dan pola radiasi hasil simulasi rancangan antena dual-layer ditunjukkan pada gambar 8 dan gambar 9 berikut.

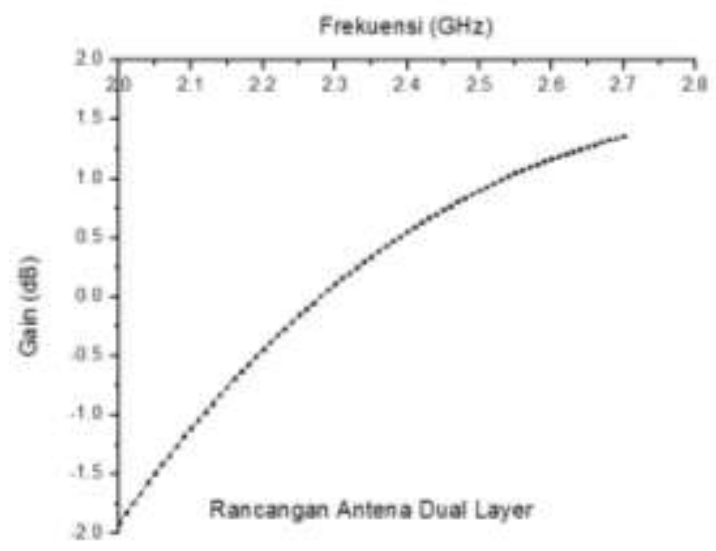

Gambar 8. Gain antena dual-layer

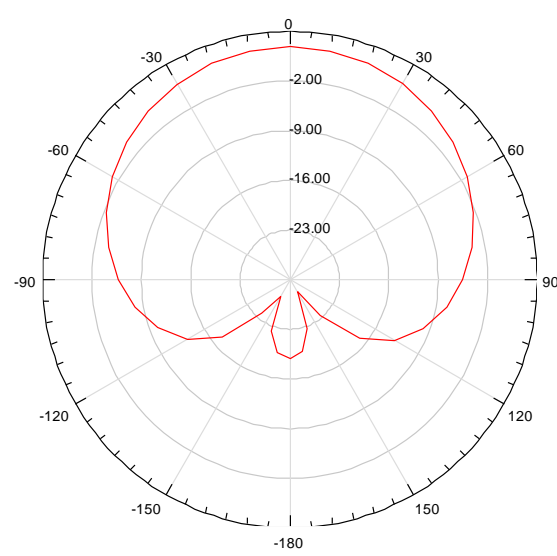

Gambar 9. Pola radiasi antena dual-layer

Kinerja dari rancangan antena dual-layer ini selanjutnya dibandingkan dengan rancangan antena single layer dengan memperhatikan capaian nilai return loss, bandwidth dan nilai gainnya. Pada gambar 10 diperlihatkan perbandingan return loss yang diperoleh untuk antena single layer dan dual-layer.

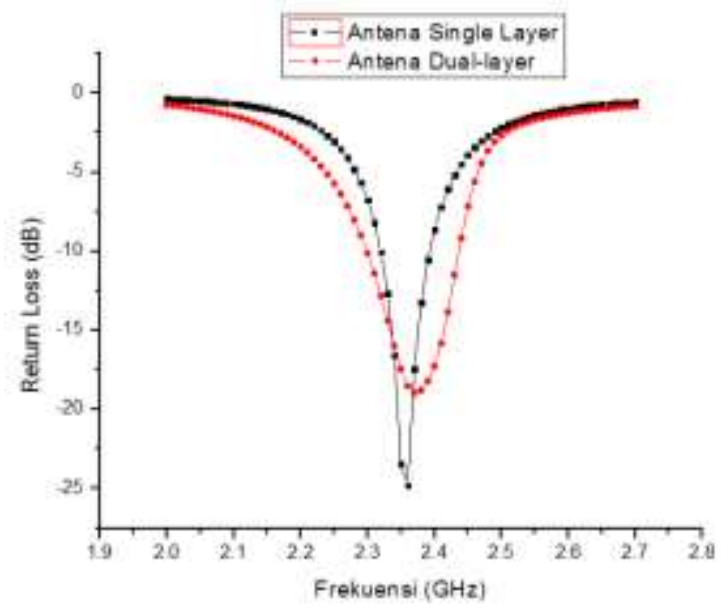

Gambar 10. Perbandingan Return Loss antara antena single layer dan dual-layer

Perbandingan kinerja antara antena single layer dan antena dual layer disajikan dalam tabel 2 berikut.

Tabel 2. Perbandingan kinerja antena single layer dengan antena dual-layer

\begin{tabular}{|c|c|c|c|}
\hline No & Parameter & Single layer & Dual-layer \\
\hline 1 & $\begin{array}{c}\text { Return Loss } \\
(\mathrm{dB})\end{array}$ & $-24,288$ & $-23,45$ \\
\hline 2 & Gain $(\mathrm{dB})$ & 0,5245 & 0,34 \\
\hline 3 & $\begin{array}{c}\text { Bandwidth } \\
(\mathrm{MHz})\end{array}$ & 73,2 & 107,3 \\
\hline 4 & $\begin{array}{c}\text { Pita frekuensi } \\
\text { kerja }(\mathrm{MHz})\end{array}$ & $\begin{array}{c}2319,7- \\
2392,9\end{array}$ & $\begin{array}{c}2298,8- \\
2406,1\end{array}$ \\
\hline
\end{tabular}

Pada tabel 2 diatas, walaupun nilai return loss pada rancangan antena dual-layer berkurang dari pada single layer, tetapi nilainya masih memenuhi persyaratan yang diminta yaitu $<-10$ $\mathrm{dB}$. Sedangkan gain antena dual-layer walau mengalami penurunan sebesar $0.2 \mathrm{~dB}$ namun masih tetap $\geq 0 \mathrm{~dB}$. Dengan memperhatikan nilai return loss yang dipersyaratkan, diperoleh bahwa cakupan frekuensi kerja 2298,8 MHz - 2406,1 $\mathrm{MHz}$ telah memenuhi rentang frekuensi Band 40 LTE.

Pada gambar 9, dapat dilihat bahwa pola radiasi dari antena dual-layer yaitu pola directional, sehingga memenuhi pola yang diharapkan. Secara keseluruhan hasil yang ditunjukkan oleh rancangan memperlihatkan bahwa penerapan dual-layer substrat meningkatkan bandwidth dari antenna yang dirancang. 


\section{Kesimpulan}

Penelitian ini telah menghasilkan rancangan antena mikrostrip circular dengan dual-layer substrat yang bekerja pada frekuensi band 40 LTE. Hasil simulasi menunjukkan antenna tersebut memiliki parameter sebagai berikut, reflection loss $=-23.45 \mathrm{~dB}$ dan gain $=0.34 \mathrm{~dB}$ pada frekuensi tengahnya. Serta antena ini memiliki pola radiasi directional. Penggunaan dual-layer substrat telah berhasil meningkatkan bandwidth sebesar $46 \%$.

\section{Ucapan Terima Kasih (Acknowledgement)}

Penelitian ini didanai dalam kegiatan penelitian dosen jurusan teknik elektro Dana DIPA Universitas Andalas Tahun Anggaran 2017 No. 104/UN.16.09.D/PL/2017

\section{Daftar Pustaka}

[1] Peraturan Menteri Komunikasi dan Informatika Republik Indonesia No.27 Tahun 2015 tentang Persyaratan Teknis Alat dan/atau Perangkat Perangkat Telekomunikasi Berbasis Standar Teknologi Long Term Evolution. Jakarta:Menkominfo, 2015.

[2] Balanis, Constantine A. . Antenna Theory Analysis and Design, Third Edition. Amerika : Wiley-Interscience, 2005.

[3] Khayat, M., J. T.Williams, D. R. Jakson, and S. A. Long, "Mutual coupling between reduced surface-wave microstrip antennas," IEEE Transactions on Antennas and Propagation, Vol. 48, 15811593, 2000

[4] Gonzalo, R., P. de Maagt, and M. Sorolla, "Enhanced patch-antenna performance by suppressing surface waves using photonic - bandgap substrates," IEEE Transactions on Microwave Theory and Techniques, Vol. 47, No. 11, 2131-2138, 1999

[5] Boutayeb, H. and T. A. Denidni, "Gain enhancement of a microstrip patch antenna using a cylindrical electromagnetic crystal substrate," IEEE
Transactions on Antennas and Propagation, Vol. 55, No. 11, 3140-3145, 2007

[6] Llombart, N., A. Neto, G. Gerini, and P. de Maagt, "Planar circularly symmetric EBG structures for reducing surface waves in printed antennas," IEEE Transactions on Antennas and Propagation, Vol. 53, No. 10, 3210-3218, 2005

[7] Gauthier, G. P., A. Courtay, and G. H. Rebeiz, "Microstrip antennas on synthesized low dilectric-constant substrate," IEEE Transactions on Microwave Theory and Techniques, Vol. 45, 1310-1314, 1997.

[8] Pai Yen Chen and Andrea Alù, "Subwavelength Elliptical Patch Antenna Loaded With Negative Metamaterials," IEEE Transactions on Antennas and Propagation, Vol. 58, Issue. 9, 2010

[9] Przesmycki, Rafal, dkk. Wideband Multilayer Microstrip Antenna Optimization of Dielectric Parameters on Antenna Bandwidth. Microwave \& Optoelectronics Conference IMOC, 2011.

[10] B. J. Kwaha, O. N Inyang \& P. Amalu, "The Circular Microstrip Patch Antenna Design and Implementation", International Journal of Research and Reviews in Applied Sciences (IJRRAS), Vol 8, Issues 1,2011

\section{Biodata Penulis}

Rudy Fernandez, Dosen di Jurusan Teknik Elektro Fakultas Teknik Universitas Andalas sejak tahun 1999. Menyelesaikan pendidikan Sarjana pada tahun 1997 dan pendidikan Magister Teknik pada tahun 2010 di Universitas Indonesia. Bidang penelitian difokuskan pada antena dan komponen microwave.

Febrian Akbar Pratama, Alumni Jurusan Teknik Elektro Fakultas Teknik Universitas Andalas. Menyelesaikan pendidikan Sarjana pada tahun 2017. 